\title{
O SIGNIFICADO DE "FILÓLOGO" PARA GREGOS E ROMANOS
}

\author{
Bruno Fregni Basseto \\ Universidade de São Paulo
}

Resumo: Pela análise de cerca de cinqüenta textos gregos e latinos, nos quais ocorre o termo "filólogo", procurei fazer a biografia do vocábulo. A grande diversividade de significados, atribuídos a "filólogo" no decurso do séculos, levou-me a buscar a acep̧̧ão que the teriam dado os criadores do termo, os gregos, e os que o literalmente emprestam, os latinos. A pesquisa abrange textos do séc. Va. C. ao séc. VI d. C. Dadas as restrições de espaço, foram selecionados os tópicos mais claros e úteis ao objetivo deste trabalho em Aristóteles, Platão, Isócrates, Plutarco, Suetónio, Ateneu, Cícero, Séneca, Ateio Prestextato, Sexto Empírico entre vários outros. A conclusão, não de todo inesperada: o termo sempre foi polissêmico.

0 conceito de "filólogo" não é de forma alguma unívoco; divergem os autores ao defini-lo, ao determinar seu objetivo, seu campo de abrangência. Uma biografia do termo permitirá alguma apreensão de seu conteúdo semântico, embora com bastante dificuldade, sobretudo por causa da ampla gama de significados de seu segundo formante.

"Filólogo" é encontrado em Platão e Aristóteles, mas o termo sem dúvida é anterios. Trata-se de uma criação dos estóicos, em cuja filosofia se encaixa

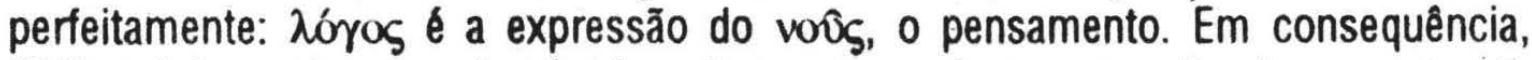
"filólogo" é aquela que, através da palavra, apreende a expressão do pensamento alheio e adquire assim conhecimentos, cultura e aprimoramento cultural.

Ora, é sabido que, pelo menos até o séc. VI a. C. , a palavra era eminentemente oral; "filólogo" era então o falante ou o ouvinte, como na escola socrática. Ao se tornar mais comum a palavra escrita com os papiros e os pergaminhos, "filólogo" passou a designar o apreciador da palavra falada, ouvida ou escrita. As múltiplas implicações do caráter permanete da palavra escrits fez com que, aos poucos, se denominasse filólogo aquele que a ela estivesse mais estreitamento ligado: o letrado, 0 autor e 0 sábio de amplos e múltiplos conhecicmentos, o que the proporciona admiração e respeito. Considera-se, por exemplo, esta passagem da Poética (1398b) de Aristóteles:

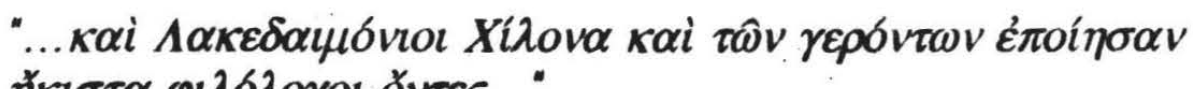

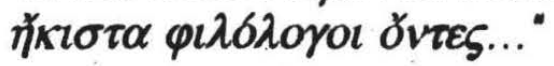

... "e os espartanos (homenagearam) a Quilão e o colocaram entre os gerontas, embora fossem bem pouco filblogos..." 
Sabe-se que Quilão foi um dos sete sábios, poeta lírico e epistológrafo (séc. VI a. C.); foi, portanto, a palavra escrita que Ihe granjeou aquela dignidade da parte de seus conterrâneos, sabidamente lacônicos.

0 termo ocorre outras vezes em Aristóteles (Problemas, 18) e em Platão (Teeteto, 146a; Fedro, 236e; Leis, 641e; Laqués, 187c e 188e; Repáblica, 582e). Em nehum desses tópicos, porém, o conteúdo semântico do termo é

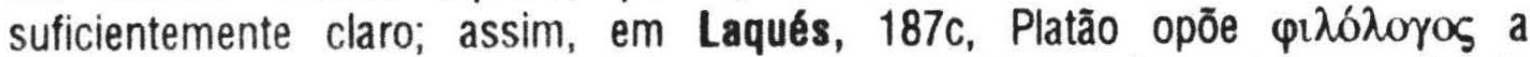

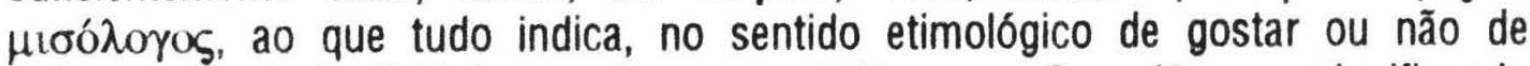

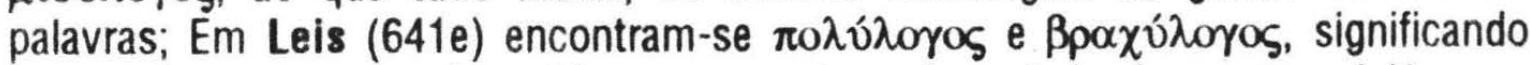

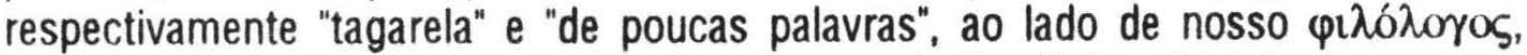
mas sem qualquer conotação pejorativa. Apenas em República (582e) o termo tem, sem dúvida, conteúdo mais especifico:

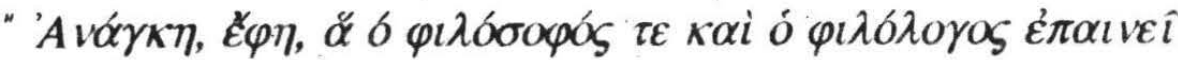 $\dot{\alpha} \lambda \eta \theta \varepsilon \sigma \tau \alpha \tau \alpha \varepsilon \hat{\imath} v \alpha \imath . "$}

"Necessariamente, diz, tudo quanto o filósofo e o filólogo aprovam é o mais verdadeiro."

0 filósofo e o filólogo são al considerados como dois especialistas, embora Platão não especifique a área de cada um; poder-se-ia pensar em conteúdo e forma respectivamente. Fica claro, porém, que o termo tendia a se especializar nas últimas obras de Platão.

Isócrates (436-338 a. C.), na obra Antídosis (XV, 296), considera a "filologia" uma grande ajuda ao trabalho educativo; e o termo, pelo contexto, sugere o sentido de "dedicação ao estudo de palvras" ou "gosto pela linguagem".

Estrabão (64 a. C. - 21 d. C.), em Geografia (2.3.7), afirma que atenienses, espartanos e tebanos não são "filólogos" por natureza, da mesma forma que babilônios e egípcios não são filósofos por natureza - mas todos por exercícios. Aqui também "filólogos"denota algo especifico, já que ser "loquaz" é algo natural para muitos em todos os povos; a oposição à filosofia leva a atribuir ao filólogo o sentido de "cultivador da palavra", em suas diversas manifestações como a retórica, a literatura $\mathrm{e}$ a linguagem em si mesma.

Em Plutarco (50-120 d. C. ) encontra-se várias vezes o termo "filólogo" (Vidas 2.17.2; Vidas Paralelas 6.2; 22.1-2; Moralia II. 133a; II. 137c). 0 seguinte tópico de Moralia (II. 133e) parece bastante elucidativo:

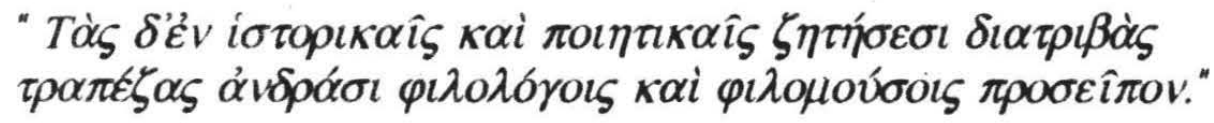

"Alguns afirmaram, de modo não odioso, que as discussóes nas investigações históricas e poéticas são uma segunda mesa para os filólogos e os amantes das musas."

Aqui os filólogos são colocados ao lado dos artistas, os "amantes das musas"; estes relacionados com a poesia e aqueles com as investigações históricas. Evocando o que se disse do sábio Quilão, poeta e epistológrafo, pode-se dizer que 0 
filólogo é o que conhece a tradição cultural falado ou escrita e que o cultivo e a ampliação desse conhecicmento the dá tanta satisfação quanto um lauto banquete. Portanto, o filólogo se identifica com o sábio, o intelectual de "multíplice e variado conhecimento". Essa última expressão é de Suetônio, ao referir-se a Ateio, que se autodenominara Filólogo, em De Grammaticis et Rhetoribus $(5,10)$ :

"Philologi adpellationem adsumpsisse videtur, quia, sic ut Eratosthenes qui primus hoc cognomen sibi vindicavit multiplici variaque doctrina censebatur."

"Parece ter tomado a denominação de filólogo porque, como Eratostenes que por primeiro revindicou para si esse cognome, era conhecido por sua múltipla e variada doutrina."

Suetônio se refere a Eratóstenes de Cirene (275-194 a. C.), discípulo de Calímaco e Lisânias; entre outras funções importantes, exerceu a de diretor da famosa Biblioteca de Alexandria. Considerado o sábio mais versátil de seu tempo,

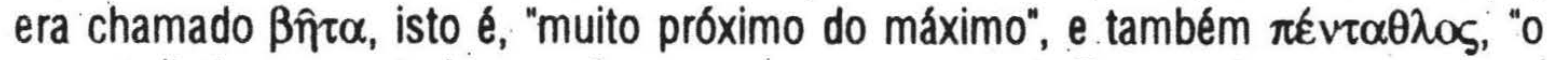
que se distingue em todos os gêneros ao mesmo tempo". De sua obra, o pouco que chegou até nós versa geografia.

Ateio Pretestado, o outro que se autodenominou filólogo, também foi polígrafo. Suetônio, na continuação da passagem acima transcrita, nos legou parte de uma epistola do próprio Ateio ao seu amigo Lélio Herma, em que esclarece a razão daquele cognome:

"Hylen nostram memento commendare, quam omnis generis coegimus, uti scis octingentos libros."

"Lembra-te de recomendar a nossa Floresta, na qual, como sabes, reunimos oitocentos livros de todos os gêneros."

Dal se depreende com a clareza o que se entendia então por filólogo: pessoa muito culta, com amplos conhecimentos nos campos mais diversos. A Nova Floresta de Bernardes pretende ser, sem dúvida, uma réplica mais moderna da Hylen de Ateio.

Sêneca (4 a.C.-65 d. C.) apresenta outro perfil do filólogo. Uma passagem bastante extensa das Cartas (Livro XVIII, 30ss) distingue bem as especialidades do filosofo, do filólogo e do gramático. Por ser longa, apenas o resumo: Ao ler o De Repáblica de Cícero, o filosofo se admira de se ter conseguido dizer tanta coisa contra a justiça. Fazendo a mesma leitura, o filologo observa que houve dois reis romanos, um dos quais não teve pai e um outro não teve mãe, pois pairam dúvida sobre a mãe de Servus e não se conhece o pai de Ancius, sendo apenas considerado neto de Numa; nota ainda que o chamado ditador, segundo os livros de história, na verdade era apelidado "mestre do povo" pela plebe e, na prática, era mestre de cavalaria; observa também que Rômulo morreu durante um eclipse do sol, e que até mesmo os reis faziam provocaçōes contra o povo, segundo consta nos livros pontificais e é igualmente 0 pensamento de peritos do porte do historiador 
Fenestella. Ao percorrer as mesmas páginas, o gramático comenta que as expressōes expse, reapse e sepse foram de fato usadas por Cícero; contrapōe arcaismos, como cretam por calcem, mostra influências, empréstimos e plágios entre autores como Homero, Virgllio e ênio.

Sêneca parece identificar o filologo com o crítico e o historiador modernos, enquanto o gramático se preocupa com fatos estritamente ligados à linguagem e a problemas literários. 0 filólogo está às voltas com conteúdos de escritos: livros pontificais, de história e de aruspícios. Suas observações são análises, deduções, inter-relacionamentos de fatos antes estudados - características e índices de cultura própria do sábio, como Eratóstenes e Ateio.

Contudo, essa acepção de "filólogo" não é unânime. Em vista da amplitude de seu campo de atuação, compreendem-se posiçōes e conceituações divergentes, conforme se realça um ou outro aspecto sem exclusão dos outros. Desde as primeiras atestações, porém, está implícito o texto escrito, sem que isso implique exclusão de outras modalidades de expressão do pensamento, como a palavra falada ou ouvida. Considere-se, por exemplo, o seguinte texto de Vidas Paralelas (2.22) de Plutarco:

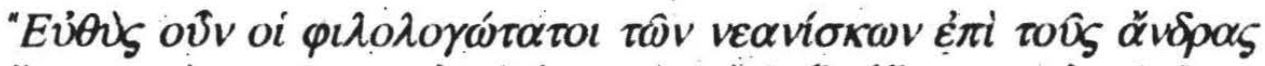

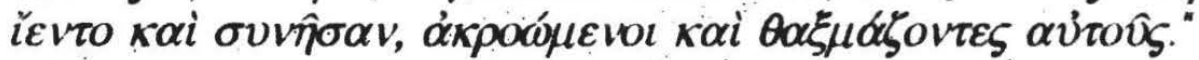

"Então os mais "filologos" dos jovens logo se aproximaram e cercaram os homens, ouvindo-os com atenção e admirando-os."

Os homens, de que fala Plutarco, eram filósofos ligados a Carnéades, 0 Acadêmico, e a Diógnes, o Filósofo, vindo a Roma em missão diplomática. Os "filólogos"- no superlativo - são jovens romanos que desejavam talvez ver e conhecer os famosos filósofos. É óbvio que o termo aqui designa algo bem diferente do que quando aplicado a Eratóstenes ou a Ateio; poder-se-ia pensar em algo como "muito interessado em aprender" ou mesmo "os mais bem falantes", no sentido etimológico.

Outras vezes tem o sentido de "culto", "refinado" no campo claramente lingüíistico, como no seguinte tópico de Sexto Empírico (c. 200 d.C), em Прòs

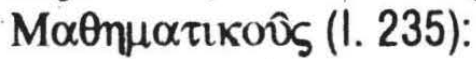

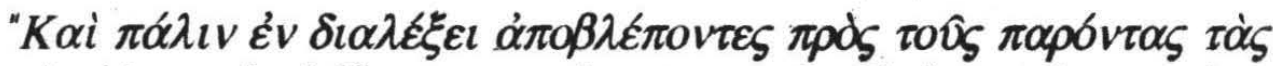

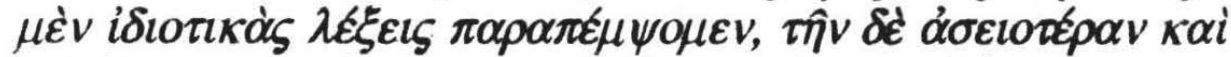

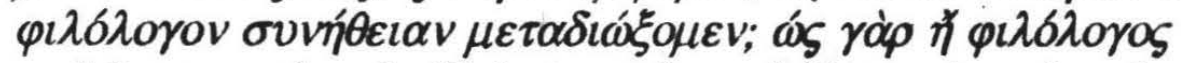

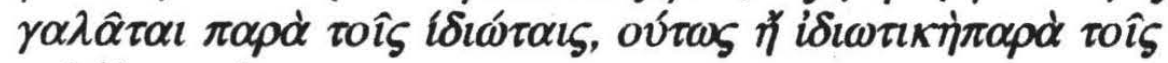

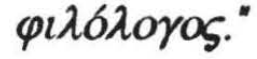

"E, de novo, numa dissertação, tendo em vista os presentes, procuraremos as expressôes mais adequadas e cultas ("filologicas") e deixaremos de lado as expressóes mais comuns, pois, como o uso culto é ridicularizado pelos adeptos do comun, da mesma forma o uso comum o é pelos do culto." 
0 autor atribui a "filólogo" uma acepção com a qual designamos hoje a norma culta, em oposição à norma popular, numa clara percepção de que uma mesma língua apresenta diversos niveis relacionados com as classes sociais.

Outra referência a essa implicação do filólogo com a linguagem e seus niveis encontra-se em Do Sublime (XXIX.2) de Longino (213-273 d. C. ), em uma

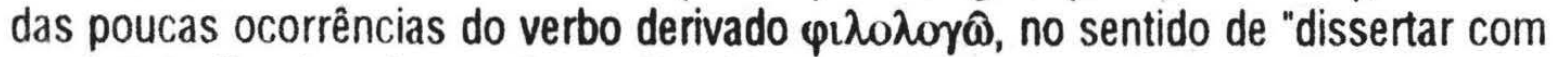
erudição". Em Longino e Sexto Empírico, o filólogo se aproxima, portanto, do gramático no sentido grego e latino, já que deve conhecer a língua em suas diversas normas e saber usá-las de modo adequado, mas os conhecicmentos expressos são pressupostos e próprios do filólogo. Vê-se que o termo significa aqui algo diferente do atribuldo a Eratóstenes e a Ateio, embora a relação semântica seja facilmente estabelecida, como uma derivação por polissemia do significado etimológico.

Entretanto, ao lado dessa especificidade semåntica, menor ou maior, o termo é encontrado também sua acepção etimológica de "loquaz" e "tagarela", como em Os Deipnosolistas (39b) de Ateneu (séc. II-III d. C.):

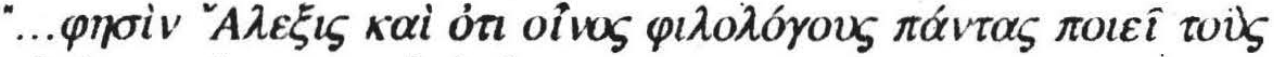

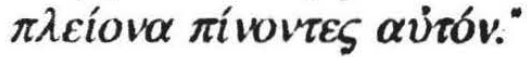

"... Alexis diz também que o vinho torna loquazes a todos os que 0 bebem em maior quantidade."

É a notória loquacidade de muitos quando se embriagam, conforme também o contexto sugere; por isoo, não parece admissivel nem aceitável a tradução "ami des Lettres" (amigo das letras) que lhe dá A. M. Desrousseaux na edição de Les Belles Lettres, a não ser no sentido jocoso ou pejorativo. A propósito, um interessante jogo de palavras de Zenão nos foi legado por Stobeu (séc. V d. C.) em Florilégio (36. 26) :

"Z

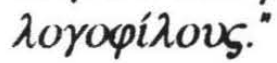

"Zenão dizia dos alunos que uns eram filologos enquanto outros eram logofilos."

0 filólogo não se restringe à forma, ao som, ao falar por falar, mas capta o conteúdo da palavra, que the enriquece a cultura e the amplia os conhecicmentos e os horizontes, enquanto o logófilo é certamente o tagarela inconseqüente; os termos denotam 0 interessado, para quem palavras são ruldos que the tornam a solidão menos opressiva, ou talvez, à maneira parnasiana, aprecia sosmente a sonoridade encantatória da linguagem. Em todo caso, é evidente, a meu ver, o sentido

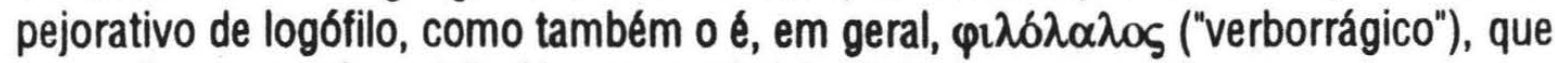
nunca foram, porém, atribuídos ao verdadeiro filólogo.

Deduz-se exposto que, mesmo entre os autores gragos e latinos, falta univocidade ao termo "filólogo"; as discrepâncias não são essenciais em todo caso. A partir do significado etimológico de "amigo da palavra", "amante do falar", seu campo semântico se amplia bastante, passando a abranger tudo o que se refere ao 
da comunicação pela linguagem em qualquer de suas formas. Nessa acepção abrangente se acomodam todas as variedades semânticas, até a atribuição do qualificativo aos sábios "de múltipla e variada doutrina", na expressão de Suetônio.

Embora os latinos tenham posições muito semelhantes às de seus mestres gregos, certamente não será inútil verificar, além do que já se viu, outras possiveis contribuições ao esclarecimento semântico do termo. Assim, a conhecida cultura helênica de Marcos Túlio Cícero transparece sobretudo em suas cartas, como em Ad Alticum (XII. 13.3), em que emprega o termo em caracteres gregos:

"Quod ad me de Varrone scribis, scis me antea orationes aut aliquid id genus solitum scribere, ut Varronem nusquam possem intexere. Postea

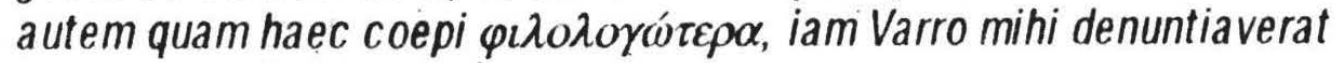

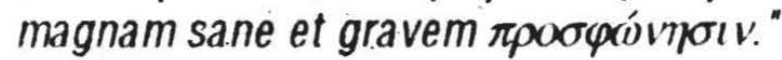

"O que me escreves a respeito de Varrão, tu sabes que anteriormente eu estava acostumado a escrever discursos ou algo desse gênero, de forma que de modo algum eu consegui inserir o Varrão. Mas depois que dei início a estas mais filológicas, já Varrão me previra um sério e certamente importante pronunciamento."

Cícero compara os discursos, que antes escrevia, com obras de outros gêneros, que passou a escrever, e considera as últimas mais filológicas que aqueles; ora, conhecemos o caráter altamente literário de sua oratória. Qual seria então o significado do comparativo "mais filológicas"? Levando em conta o caráter mais pragmático do gênero oratório - a favor ou contra alguém ou algo - "mais filológico" em relação aos outros gêneros literários deve relacionar-se, certamente, com a gratuidade dos temas abordados, como destino, amizade, velhice, natureza dos deuses, em que se busca apenas a cultura e o exercício do raciocónio. Com isso, Cícero se traduziu nem transliterou certamente por não encontrar no latim um termo semanticamente correspondente, No mesmo epistolário Ad Atticum (XIII. 12. 3 ), o termo volta a ocorrer com a mesma acepçāo, ao que tudo indica:

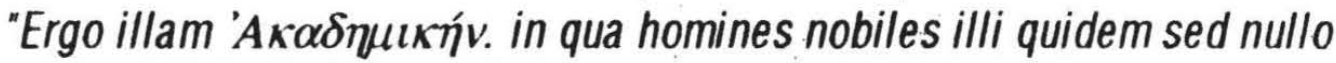
modo philologi nimis acute loquuntur, ad Varronem transferamus."

"Portanto, transfiramos para Varrão aquela Acadêmica na qual aqueles homens, nobres sem dúvida, mas de forma alguma filologos, fala de modo por demais contundente."

Distingue-se a nobreza da cultura; os homens são certamente nobres, mas não têm o refinamento intelectual requerido pelo ambiente acadêmico, isto é, não são filólogos, o que é denunciado pelo modo de falar.

Quando o cristianismo se impõe, começ a rarear a ocorrência do termo. Não é encontrado em Agostinho (354-430 d.C. ) nem em Anício Mânlio Serverino Boécio (480-524), em Flávio M. Aurélio Cassiodoro (490-583) ou em Izidoro de Sevilha (602-634), cujas Etymologiae, embora quase enciclopédicas, não fazem qualquer menção à filologia. Desse período destaca-se somente Marciano Capella 
com De Nuptiis Mercurii et Philologiae na primeira metade do séc. V. A obra é uma espécie de alegoria, na qual a Filologia, cercada ancilarmente pelas sete artes, sobe ao céu para se casar com Mercúrio, o deus da eloqüência. A filologia al deve ser entendida no sentido grego do conhecicmentos vastos e múltiplos, o que inclui as artes, sobretudo a literatura.

Tudo indica, portanto, que o termo "filólogo" e seus derivados "filologia" e "filologar" deixaram de ser correntes a partir do séc. VI no Ocidente. A nova mentalidade cristã levou os estudiosos a outra visão do mundo, cujo enfoque principal eram os problemas religiosos; tentava-se suprimir tudo quanto não se pudesse cristianizar. Ocorre então um hiato na biografia do termo. Só em 1396, portanto depois de setecentos anos, Emmanuel Chrysolora vem de Constantinopla a Florença para restauras os estudos clássicos e o termo volta a aflorar, com os primeiros sinais do Renascicmento. No séc. XVI, os Escalígeros, Júlio César e José Justo, podem ser considerados verdadeiros filólogos por seus conhecicmentos, buscados em grande parte na antigüidade clássica; posteriormente, o número dos filólogos autênticos se multiplica.

Em conclusão, a falta de univocidade do termo "filólogo" na prática sempre existiu; não o definiram os gregos, seus criadores, nem os latinos. Usaramno polissemicamente, do etimológico "amigo da palavra" a detentor de todo o universo de conhecimentos, que a palavra produziu através dos tempos, com toda a gama de significados intermediários, incluindo a própria linguagem e sua expressão mais estilizada, a arte literária. Assim deve ser entendida a definição de Filologia de August Boeckh (1785-1867): "Philologie ist die Erkenntnis des Erkanten". ("Filologia é o conhecicmento do conhecido"). Ou a de Ernest Renan (Renan, 1849, pag. 138): "La philologie (...) est ja science des produits de l'esprit humain." ( "A filologia é a ciência dos produtos do espirito humano".)

RÉsume: Par l'analise d'à peu près cinquante textes grecs et latins, dans les quels on trouve le mot "philologue", j'ai cherché à esquisser la biographie de ce mot. La très grande diversité de signifiés, donnés à "philologue" pendant les siècles, m'a mené à chercher l'acception que lui auraient donnée les créateurs du terme, les grecs, et ceux qui l'ont littéralement assumé, les latins. La période étudiée va du V siècle av. J. C. jusqu'au VI apr. J. C. En raison des restrictions d'espace, il a fallu choisir, parmiles textes, les plus claires et les utiles a notre dessein chez Aristote, Platon, Ateius Praetextatus, Sextus Empiricus et autres. On est arrivé à la conclusion, pas tout à fait inattendue: le mot a toujours été polyssémique.

\section{Bibliografia}

Os textos dos autores gregos e latinos foram extraídos de edições críticas diversas de Les Belles Lettres (Paris), ou da Garnier (Paris), ou da LOEB (Londres), ou ainda da Teubner (Leipzig), cujas edições sucessivas foram comparadas. 
AMADOR, E. M. Martinez. Diccionário Gramatical. Barcelona: Ed. Ramón Sopena, 1954.

BAILLY, A. Dictionnaire grec-français. Paris: Hachette, 1963.

ERNOUT, A. et MEILLET, A. Dictionnaire étymologique de la langue latine. Paris: Éd. Klincksieck, 4. éd. , 1979.

HAMMOND, N. G. L. and SCULLARD, H. H. The Oxford Classical Dictionary. Oxford: Clarendon Press, 2. ed. , 1989.

MEYER-LÜBKE, W. Romanisches Etymologisches Wörterbuch. Heidelberg: Carl Winter Universitätsverlag, 5. Auflage, 1972.

RENAN, Ernest. L'avenir de la science. Paris: Calmann-Levy Éd. , 1849.

UHLIG, Gustav. Apollonii Dyscoli quae supersunt de Constructione libri quattuor. Lypsiae: Teubner, 1910. 